\title{
Reliability and validity of the ESRD Symptom Checklist - Transplantation Module in Norwegian kidney transplant recipients Knut Stavem ${ }^{* 1,2}$ and Rüdiger Ganss ${ }^{1}$
}

\author{
Address: ${ }^{1}$ Medical Department, Akershus University Hospital, Lørenskog, Norway and ${ }^{2}$ Helse-Øst Health Services Research Centre, Lørenskog, \\ Norway \\ Email: Knut Stavem* - knut.stavem@klinmed.uio.no; Rüdiger Ganss - rudiger.ganss@ahus.no \\ * Corresponding author
}

Published: 16 November 2006

BMC Nephrology 2006, 7:17 doi:10.1186/147|-2369-7-17

This article is available from: http://www.biomedcentral.com/147/-2369/7/17

(C) 2006 Stavem and Ganss; licensee BioMed Central Ltd.

This is an Open Access article distributed under the terms of the Creative Commons Attribution License (http://creativecommons.org/licenses/by/2.0), which permits unrestricted use, distribution, and reproduction in any medium, provided the original work is properly cited.
Received: 22 June 2006

Accepted: 16 November 2006

\begin{abstract}
Background: The aim of the study was to validate the Norwegian version of a self-administered 43-item questionnaire designed to assess quality of life in kidney transplant recipients, the End-Stage Renal Disease Symptom Checklist - Transplantation Module (ESRD-SCL).

Methods: In total, 53 kidney transplant recipients from one university-affiliated hospital responded to a questionnaire including the ESRD-SCL and the Short Form 36 (SF-36). We assessed internal consistency reliability and test-retest reliability with 2 weeks between assessments. Construct validity was assessed by correlations of the ESRD-SCL subscales with related and unrelated SF-36 scales, demographic, and clinical characteristics.

Results: Subscales of the ESRD-SCL showed good internal consistency reliability (Cronbach's = $0.72-0.8 \mathrm{I}$ ) and for the aggregate total scale $\alpha$ was 0.94 . Test-retest reliability median I 4 days apart was excellent with intraclass coefficients ranging from 0.87 to 0.95 . The pattern of correlations of the ESRD-SCL scales with related and unrelated scales SF- 36 scales and demographic and clinical characteristics gave support to the construct validity of the ESRD-SCL.

Conclusion: The Norwegian translation of the ESRD-SCL showed satisfactory internal consistency reliability, test-retest reliability and construct validity, at the level of the original German version.
\end{abstract}

\section{Background}

Kidney transplantation has a positive impact on survival and morbidity of patients with end-stage renal disease. Recently, there has been increasing attention to healthrelated quality of life (HRQoL) as an important consideration in evaluating the impact of kidney transplantation. Kidney transplant recipients have better HRQoL than transplant candidates maintained on hemodialysis $[1,2]$, and they experience an improvement of HRQoL in the first months after transplantation $[3,4]$.
The HRQoL in kidney transplantation can be evaluated using generic tools, such as the Sickness Impact Profile (SIP), the Nottingham Health Profile (NHP) or the Short Form 36 (SF-36) [5]. Some disease-specific tools for evaluation of HRQoL in relationship to renal transplantation have been developed, including the Kidney Transplant Questionnaire [6], and the ESRD symptom checklist transplantation module (ESRD-SCL) questionnaire [7]. Also, the Kidney Disease-Quality of Life (KDQOL) questionnaire is commonly used [8-10], although it was not 
developed specifically for the evaluation of transplantation.

To conduct studies on HRQoL outcomes in kidney transplant patients, it is necessary to adapt relevant questionnaires and tools to the appropriate language and assess the psychometric properties of the questionnaires in relevant populations. Based on content analysis and available documentation, we identified the ESRD-SCL as a feasible questionnaire for use in kidney transplantation, in particular to evaluate the effects of immunosuppressant medication [11].

The objective of the present study was to assess the reliability and construct validity of a Norwegian version of the ESRD-SCL in renal transplant recipients.

\section{Methods}

\section{Subjects and study design}

Kidney transplantation in Norway is centralized to Rikshospitalet University Hospital, Oslo; however, follow up is decentralized and performed in several hospitals. In the present study we aimed at including all consecutive kidney transplant recipients in a population of about 65 recipients, who regularly visits the nephrology outpatient clinic at Akershus University Hospital, irrespective of medication and time since transplantation. During an outpatient visit, the attending physician asked the patients to participate and to give their written informed consent. The participants received a package of self-administered questionnaires to be filled in at home and mailed to the study organizers. About 2 weeks after returning the questionnaires, the respondents received another identical questionnaire by mail. We contacted eight of the participants by telephone, as a reminder after the first questionnaire administration. No reminders were used for the retest.

We aimed at including 60 subjects in order to have data from 50 subjects for analysis. In total 59 patients accepted to participate; 53 returned the first questionnaire $(90 \%)$, and 48 the second questionnaire (81\%). The Regional committee for medical research ethics, Health Region East (REK Øst) approved the study, and the participants signed a declaration of informed consent.

\section{Questionnaires}

The package of questionnaires contained the following instruments:

The ESRD symptom checklist - transplantation module (ESRD-SCL) The ESRD-SCL was developed in Essen, Germany to assess quality of life after renal transplantation, focusing on transplantation-specific symptoms, side effects of immunosuppressive therapy and psychological distress [7]. It is available in German, English and Turkish versions [12]. The reliability, validity and responsiveness of this questionnaire have been assessed in a German population of renal transplantation patients $[7,13]$, and the questionnaire has been used to compare HRQoL of patients using tacrolimus and ciclosporin-microemulsion [11].

The cultural and language adaptation of the ESRD-SCL was done according to a recommended procedure [14]. Two Norwegian physicians fluent in German in parallel translated the questionnaire into from German into Norwegian. A group with the two translators and two other members discussed the translations and agreed on a consensus version. This consensus version then was backtranslated into German by a physician fluent in Norwegian, but with German as his native language. The backtranslated version was compared with the original and discussed with the authors of the original version. The questionnaires were considered conceptually and linguistically equivalent. Before using the questionnaire, it was pilot-tested in some patients with kidney failure and found to be acceptable. The final Norwegian version of the questionnaire is presented as an appendix [see Additional file 1].

\section{Short Form 36 (SF-36)}

The general health status questionnaire SF-36 intends to assess aspects of health important to all patients. The SF36 is developed in the U.S., contains eight scales [15,16], and two component summary scales, and has been extensively validated; however with limited experience in kidney transplant recipients. We used the Norwegian standard SF-36 version 1.2 [17], assessing health status during the past four weeks. The scales were scored from 0 (lowest level of functioning) to 100 (highest level of functioning). The SF-36 has previously been used in Norwegian kidney transplant recipients [18], and its psychometric properties have been demonstrated in Norwegian patients and scores for a normal population presented $[17,19]$.

\section{Demographic and clinical variables}

At study entry, the attending physician recorded information on the patients's renal disease, previous transplantations, time since transplantation, current medication, data from the most recent physical examination including height, weight, blood pressure, and comorbidity using Charlson's comorbidity index, and some laboratory tests (Hemoglobin, S-creatinine). In the self-administered questionnaire, the patients reported some supplementary demographic data, such as marital status, education, and employment status. 


\section{Statistical analysis}

Descriptive statistics are presented using the mean (SD), median (range) or numbers (\%). Internal consistency reliability was assessed using Cronbach's $\alpha$ [20]. Test-retest reliability was assessed over 2 weeks with an intraclass correlation coefficient (ICC), using the average of raters in a two-way mixed model ICC with absolute agreement definition.

Construct validity for the ESRD-SCL subscales was assessed by comparing actual correlations with the SF-36 scales with apriori predicted correlations. Based on previous literature $[7,21]$ and content analysis of the items of the scales, we hypothesized that:

(1) The two ESRD-SCL dimensions Limited cognitive capacity and Transplantation-associated psychological distress would have the highest correlations with the SF36 scale Mental health.

(2) The correlation of the ESRD-SCL dimension Cardiac and renal dysfunction would be highest with the SF-36 scale Physical functioning.

(3) The correlations between the two scales measuring medication side effects and the SF-36 scales would be weak.

(4) Associations with sociodemographic and clinical data would be highest for employment, age, sex, time since transplantation, and comorbidity, possibly in the range $0.08-0.30$ roughly equivalent to an incremental $\mathrm{R}^{2}$ of 0.006-0.09 [7]. For comorbidity we used the Charlson comorbidity index (range 2-8) [22]. We also investigated the association with Hemoglobin, S-creatinine and immunosuppressive regimen (tacrolimus/prednisolone vs. ciclosporin/prednisolone), possibly being able to capture the characteristic side effects of ciclosporin of gum and hair growth.

For correlations between the ESRD-SCL and SF-36 scales we used Pearson's correlation coefficient. For correlations of the ESRD-SCL scales with demographic and clinical variable we used Spearman's rank correlations, because of the ordinal nature of some of the data and the dichotomy of some variables.

Finally, we assessed the capacity of the questionnaire subscales subscales to discriminate between two known groups, as defined by: (1) immunosuppressive regimen, comparing tacrolimus/prednisolone $(\mathrm{n}=9)$ with ciclosporin/prednisolone ( $\mathrm{n}=39$ ); (2) Age below/above the sample median of 57.87 years; (3) comorbidity, using Charlson comorbidity index above/below the median $(\leq 2$ vs $>2$ ). These or similar variables have been associated with HRQoL following renal transplantation in previous studies $[7,21]$. In this analysis we used analysis of variance/covariance, adjusting for age, sex and comorbidity (Charlson comorbidity index $\leq 2$ vs $>2$ ), where appropriate.

Sample size for test-retest analysis was planned to about 50 patients, which is commonly used in the literature. However, formal sample size calculation for test-retest analysis or correlation analysis is rarely done and was not carried out in the present study. We chose a 5\% significance level, using two-sided tests. The SPSS statistical software version 12.0 (SPSS Inc., Chicago, IL) was used for all analyses.

\section{Results}

The characteristics of the 59 respondents are shown in Table 1. ESRD-SCL and SF-36 scores are shown in Table 2, including the percentage of respondents giving lowest (floor) and highest possible score (ceiling). The ESRDSCL scores did not concentrate at the ceiling for any subscale. However, scores concentrated at the floor for the Limited cognitive capacity, Side effects of corticosteroids, and Increased growth of gum and hair subscales (Table 2). For the SF-36 scales role - physical 30\% of respondents scored the lowest possible value (floor). There were marked ceiling effects on the SF-36 scales role - physical (40\%), bodily pain (25\%), social functioning (50\%), and role - emotional (67\%) scales (Table 2 ).

The Cronbach's $\alpha$ was high for all dimensions of the ESRD-SCL $(\alpha=0.72-0.81)$, for the total scale $(\alpha=0.94)$ (Table 2), and for the scales of the SF-36 ( $\alpha=0.80-0.91)$. In the test-retest the respondents $(n=48)$ completed questionnaires median 14 days apart (interquartile range 9 to 20 days). In the test-retest, the intraclass correlation coefficients for the different subscales of the ESRD-SCL ranged 0.87 to 0.95 , and for the SF-36 from 0.83 to 0.95 .

In the assessment of construct validity, the hypothesized associations between scales of the ESRDL-SCL generally were among the highest, largely confirming the hypothesis, although some of the other subscales also correlated well (Table 3). The correlations of the two scales measuring medication side effects with the SF-36 scales were among the weakest pairwise correlations.

Among the demographic and clinical variables, employment showed the highest correlation with most of the ESRDL-SCL subscales, although these correlations were all weak and $<0.40$ (Table 4 ). Increased growth of gum and hair, a typical side effect of ciclosporin, was moderately associated with a ciclosporin-containing immunosuppressive regimen. With the above exceptions, associations of the ESRDL-SCL subscales with demographic and clini- 
Table I: Respondents' characteristics $(n=53)$, mean (SD) unless otherwise stated

\begin{tabular}{|c|c|}
\hline Age, years & $57.5(13.2)$ \\
\hline Female gender, number (\%) & $22(42)$ \\
\hline Married/cohabiting, number (\%) & $40(76)$ \\
\hline \multicolumn{2}{|l|}{ Education in years, number (\%) } \\
\hline$<10$ & $17(32)$ \\
\hline $10-12$ & $22(42)$ \\
\hline$>12$ & $12(26)$ \\
\hline Body mass index, $\mathrm{kg} / \mathrm{m}^{2}$ & $26.8(5.8)$ \\
\hline Systolic blood pressure, $\mathrm{mmHg}$ & $131(15)$ \\
\hline Diastolic blood pressure, $\mathrm{mmHg}$ & $78(8)$ \\
\hline S-creatinine, $\mu \mathrm{mol} / \mathrm{L}$ & $136(74)$ \\
\hline Hemoglobin, g/dL & $13.6(1.6)$ \\
\hline \multicolumn{2}{|l|}{ Employment, number (\%) } \\
\hline Full-time employed & $18(34)$ \\
\hline Part-time employed & $3(6)$ \\
\hline On sick-leave & $4(8)$ \\
\hline Disability pension & $15(28)$ \\
\hline Retired because of age & II (2I) \\
\hline \multicolumn{2}{|l|}{ Other } \\
\hline \multicolumn{2}{|l|}{ Diagnosis, number (\%) } \\
\hline Glomerulonephritis & $19(36)$ \\
\hline Polycystic disease & $14(26)$ \\
\hline Hypertensive renal disease & $7(13)$ \\
\hline Diabetic nephropathy & $7(13)$ \\
\hline Other & $6(12)$ \\
\hline \multicolumn{2}{|l|}{ Type of transplantation, number (\%) } \\
\hline Cadaveric & $32(60)$ \\
\hline Living donor & $21(40)$ \\
\hline \multicolumn{2}{|l|}{ Immunosuppression, number (\%) } \\
\hline Ciclosporin A & $40(76)$ \\
\hline Tacrolimus & $10(19)$ \\
\hline Mycophenolate mofetil & $20(38)$ \\
\hline Azathioprine & $14(26)$ \\
\hline Prednisolone & $51(96)$ \\
\hline \multicolumn{2}{|l|}{ Blood pressure medications, number (\%) } \\
\hline 0 & $18(34)$ \\
\hline 1 & $9(17)$ \\
\hline 2 & $14(26)$ \\
\hline $3+$ & $12(23)$ \\
\hline Charlson comorbidity index, median (range) & $2(2-8)$ \\
\hline Time since transplantation, years (median (range)) & $4.4(0.4-29.1)$ \\
\hline
\end{tabular}

cal variables were weak or close to nothing, as hypothesized (Table 4).

Only the ESRD-SCL subscale Increased growth of gum and hair discriminated between patients with two different immunosuppressive regimens after adjustment for age, sex, and comorbidity (Table 5). Only the two SF-36 scales Role - physical and Bodily pain discriminated between patients below/above the median age in the multivariate model. On the ESRD-SCL subscale Side effects of corticosteroids, younger patients tended indicate more problems than those above the median age, although this difference was statistically not significant (Table 5). The
SF-36 physical functioning scale was the only scale that discriminated between patient groups according to Charlson comorbidity index $\leq 2 \mathrm{vs.}>2$ ( $\mathrm{p}=<0.001)$. The ESRDSCL subscales Limited physical capacity and Cardiac and renal dysfunction showed differences that were almost statistically significant (Table 5), however, we hypothesized that these scales were associated with the Physical functioning scale of the SF-36.

\section{Discussion}

In this cross-sectional study, the Norwegian version of the ESRD-SCL demonstrated high internal consistency reliability for all six subscales, in line with the original German version ( $\alpha=0.76-0.85)$ [7]. Furthermore the test-retest reliability over 2 weeks for all scales was excellent. Reproducibility for the scales of this questionnaire has previously only been assessed over 1 year in stable patients [7]. It has been suggested that HRQoL instruments can be used for comparisons at group level if reliability is above 0.70 [23]. All subscales of both the ESRD-SCL and the SF36 instruments had higher internal consistency reliability than this. For use at the level of the individual patient, a suggested minimum requirement for reliability is 0.90 while 0.95 is desirable [23] although perhaps too stringent [24].

The pattern of correlations between the two instruments largely confirmed hypothesized associations from literature review and item content analysis, hence supporting convergent and discriminant validity of the ESRD-SCL [25]. Furthermore, the associations of the ESRD-SCL subscales with demographic and clinical variables were in line with expectations. The patients accepted the questionnaire well, as demonstrated by the high completion rates.

We found no difference in HRQoL between a tacrolimusbased and a ciclosporin-based regimen using the SF-36, and no systematic difference on the ESRD-SCL subscales except the Increased growth of gum an hear subscale, however our sample was small. Previous studies have reported comparable effects on global HRQoL of the two regimens, while Tacrolimus has tended to improved the disease-specific HRQoL [11,26-30].

A previous study has reported lower scores, denoting less side effects, on the Side effects of corticosteroids dimension of the ESRD-SCL and more suffering in the Limited cognitive function and Increased growth of gum and hair dimension among the elderly [7]. In the present study we noted a statistically nonsignificant tendency to lower Side effects of corticosteroids in the elderly, however there was no indication of a difference according to age in the Limited cognitive dimension or Increased growth of gum and hair dimension in the present study. 
Table 2: Health-related quality of life scores and relaibility assessments

\begin{tabular}{|c|c|c|c|c|c|c|c|c|c|c|}
\hline & \multirow[b]{2}{*}{$\mathrm{n}$} & \multicolumn{7}{|c|}{ Scores } & \multicolumn{2}{|c|}{ Reliability } \\
\hline & & Items & Minimum & Maximum & Mean & SD & \%min (floor) & \%max (ceiling) & Internal consistency* & Test-retest** \\
\hline \multicolumn{11}{|l|}{ ESRD-SCL (range 0-4) } \\
\hline Limited physical capacity & 53 & 10 & 0.10 & 2.50 & 0.74 & 0.54 & 0 & 0 & 0.80 & 0.95 \\
\hline Limited cognitive capacity & 53 & 8 & 0 & 2.00 & 0.56 & 0.48 & 13 & 0 & 0.80 & 0.93 \\
\hline Cardiac and renal dysfunction & 53 & 7 & 0 & 2.57 & 0.71 & 0.59 & 6 & 0 & 0.81 & 0.90 \\
\hline Side effects of corticosteroids & 53 & 5 & 0 & 2.20 & 0.60 & 0.57 & 21 & 0 & 0.72 & 0.94 \\
\hline Increased growth of gum and hair & 53 & 5 & 0 & 3.80 & 0.72 & 0.80 & 13 & 0 & 0.80 & 0.87 \\
\hline $\begin{array}{l}\text { Transplantation-associated } \\
\text { psychological distress }\end{array}$ & 53 & 8 & 0 & 1.88 & 0.59 & 0.46 & 6 & 0 & 0.78 & 0.87 \\
\hline Total & 53 & 43 & 0.07 & 2.07 & 0.65 & 0.43 & 0 & 0 & 0.94 & 0.95 \\
\hline \multicolumn{11}{|l|}{ SF-36 (range 0-100) } \\
\hline Physical functioning & 53 & 10 & 20 & 100 & 73.1 & 24.5 & 0 & 13 & 0.91 & 0.87 \\
\hline Role - physical & 53 & 5 & 0 & 100 & 54.7 & 43.3 & 30 & 40 & 0.89 & 0.88 \\
\hline Bodily pain & 52 & 2 & 0 & 100 & 65.3 & 28.7 & 2 & 25 & 0.91 & 0.93 \\
\hline General health & 51 & 5 & 0 & 100 & 57.5 & 26.0 & 2 & 2 & 0.85 & 0.95 \\
\hline Vitality & 52 & 4 & 5 & 95 & 54.4 & 21.0 & 0 & 0 & 0.80 & 0.90 \\
\hline Social functioning & 52 & 2 & 12.5 & 100 & 81 & 24.6 & 0 & 50 & 0.84 & 0.86 \\
\hline Role - emotional & 51 & 4 & 0 & 100 & 78.4 & 34.5 & 0 & 67 & 0.80 & 0.83 \\
\hline Mental health & 52 & 5 & 24 & 100 & 77.8 & 17.9 & 0 & 10 & 0.81 & 0.91 \\
\hline
\end{tabular}

* Cronbach's $\alpha$

** Intraclass correlation coefficient

Table 3: Multitrait-multimethod correlation matrix. Pearson's correlation coefficients between subscales of the ESRD-SCL and SF-36 ESRD-SCL

\begin{tabular}{|c|c|c|c|c|c|c|c|}
\hline$n$ & $\begin{array}{l}\text { Limited } \\
\text { physical } \\
\text { capacity }\end{array}$ & $\begin{array}{l}\text { Limited } \\
\text { cognitive } \\
\text { capacity }\end{array}$ & $\begin{array}{l}\text { Cardiac and renal } \\
\text { dysfunction }\end{array}$ & $\begin{array}{l}\text { Side effects of } \\
\text { corticosteroids }\end{array}$ & $\begin{array}{l}\text { Increased growth } \\
\text { of gum and hair }\end{array}$ & $\begin{array}{l}\text { Transplantation-associated } \\
\text { psychological distress }\end{array}$ & Total \\
\hline
\end{tabular}

\begin{tabular}{|c|c|c|c|c|c|c|c|c|}
\hline \multicolumn{9}{|l|}{ SF-36 } \\
\hline Physical functioning & 53 & $-0.54 * *$ & $-0.38 * *$ & $-0.4 I * *$ & $-0.38 * *$ & -0.26 & $-0.38 * *$ & $-0.52 * *$ \\
\hline Role - physical & 53 & $-0.52^{* *}$ & $-0.43^{* *}$ & $-0.28^{*}$ & -0.04 & -0.14 & -0.27 & $-0.39 * *$ \\
\hline Bodily pain & 52 & $-0.74^{* *}$ & $-0.5 I^{* *}$ & $-0.52 * *$ & $-0.33^{*}$ & $-0.31 *$ & $-0.50 * *$ & $-0.65 * *$ \\
\hline General health & 51 & $-0.59 * *$ & $-0.4 I^{* *}$ & $-0.55 * *$ & $-0.32 *$ & $-0.29 *$ & $-0.38 * *$ & $-0.57^{* *}$ \\
\hline Vitality & 52 & $-0.69 * *$ & $-0.49 * *$ & $-0.44 * *$ & -0.26 & $-0.39 * *$ & $-0.36 * *$ & $-0.60 * *$ \\
\hline Social functioning & 52 & $-0.58 * *$ & $-0.4 I^{* *}$ & $-0.28 *$ & -0.24 & -0.16 & $-0.54 * *$ & $-0.50 * *$ \\
\hline Role - emotional & 51 & $-0.67 * *$ & $-0.44^{* *}$ & $-0.31 *$ & -0.24 & -0.25 & $-0.52 * *$ & $-0.55 * *$ \\
\hline Mental health & 52 & $-0.54 * *$ & $-0.51 * *$ & -0.15 & -0.15 & -0.02 & $-0.65^{* *}$ & $-0.46 * *$ \\
\hline
\end{tabular}

$*<0.05 * *<0.01$

Table 4: Spearman's rank correlation coefficients of subscales of the ESRD-SCL with demographic and clinical variables

\begin{tabular}{|c|c|c|c|c|c|c|c|c|}
\hline & $\mathrm{n}$ & $\begin{array}{l}\text { Limited } \\
\text { physical } \\
\text { capacity }\end{array}$ & $\begin{array}{l}\text { Limited } \\
\text { cognitive } \\
\text { capacity }\end{array}$ & $\begin{array}{l}\text { Cardiac and renal } \\
\text { dysfunction }\end{array}$ & $\begin{array}{l}\text { Side effects of } \\
\text { corticosteroids }\end{array}$ & $\begin{array}{l}\text { Increased growth } \\
\text { of gum and hair }\end{array}$ & $\begin{array}{l}\text { Transplantation-associated } \\
\text { psychological distress }\end{array}$ & Total \\
\hline Age (years) & 53 & 0.22 & 0.18 & 0.18 & -0.13 & 0.08 & -0.06 & 0.09 \\
\hline Female (2) vs. male (I) & 53 & 0.10 & -0.04 & 0.25 & $0.34 *$ & -0.05 & 0.07 & 0.17 \\
\hline Employment (yes/no) & 53 & $-0.38 * *$ & $-0.30 *$ & -0.23 & -0.19 & $-0.37^{* * *}$ & -0.15 & $-0.34^{*}$ \\
\hline Time since transplantation (years) & 53 & 0.19 & -0.01 & 0.14 & -0.17 & 0.14 & -0.21 & 0.02 \\
\hline Charlson's comorbidity index & 53 & 0.24 & 0.19 & 0.20 & 0.04 & 0.03 & 0.06 & 0.17 \\
\hline Hemoglobin (g/dL) & 53 & -0.14 & -0.01 & $-0.29 *$ & -0.13 & 0.11 & -0.18 & -0.20 \\
\hline S-creatinine (umol/L) & 53 & 0.16 & 0.11 & 0.20 & -0.04 & -0.06 & 0.13 & 0.15 \\
\hline CsA (2) vs. Tacrolimus (I) & 48 & 0.08 & 0.06 & 0.06 & -0.05 & $0.48 * *$ & -0.11 & 0.08 \\
\hline No. of drugs for hypertension & 53 & 0.15 & 0.08 & 0.15 & 0.03 & -0.22 & 0.17 & 0.14 \\
\hline
\end{tabular}

$*<0.05 * *<0.01$ 
Table 5: Health-related quality of life scores according to immunosuppressive regimen, age below/above the median and comorbidity below/above the median

\begin{tabular}{|c|c|c|c|c|c|c|c|c|c|}
\hline & \multicolumn{3}{|c|}{ Ciclosporin* } & \multicolumn{3}{|c|}{ Age (years) ${ }^{* *}$} & \multicolumn{3}{|c|}{ Charlson comorbidity index*** } \\
\hline & $\begin{array}{l}\text { Tacrolimus and } \\
\text { prednisolon }\end{array}$ & $\begin{array}{l}\text { Ciclosporin and } \\
\text { prednisolon }\end{array}$ & $P$ & $\leq 58.88$ & $>58.88$ & $P$ & $\leq 2$ & $>2$ & $P$ \\
\hline$N$ & 9 & 39 & & 27 & 26 & & 30 & 23 & \\
\hline \multicolumn{10}{|l|}{ ESRD-SCL } \\
\hline Limited physical capacity & $0.62 \pm 0.18$ & $0.82 \pm 0.09$ & 0.33 & $0.73 \pm 0.11$ & $0.81 \pm 0.11$ & 0.62 & $0.63 \pm 0.10$ & $0.91 \pm 0.11$ & 0.06 \\
\hline Limited cognitive capacity & $0.45 \pm 0.15$ & $0.59 \pm 0.08$ & 0.43 & $0.57 \pm 0.10$ & $0.58 \pm 0.10$ & 0.93 & $0.46 \pm 0.09$ & $0.69 \pm 0.10$ & 0.10 \\
\hline Cardiac and renal dysfunction & $0.72 \pm 0.19$ & $0.82 \pm 0.08$ & 0.21 & $0.73 \pm 0.11$ & $0.79 \pm 0.11$ & 0.71 & $0.62 \pm 0.10$ & $0.91 \pm 0.12$ & 0.07 \\
\hline Side effects of corticosteroids & $0.67 \pm 0.18$ & $0.68 \pm 0.09$ & 0.20 & $0.71 \pm 0.11$ & $0.58 \pm 0.11$ & 0.16 & $0.53 \pm 0.10$ & $0.76 \pm 0.12$ & 0.16 \\
\hline $\begin{array}{l}\text { Increased growth of gum and } \\
\text { hair }\end{array}$ & $0.19 \pm 0.27$ & $0.92 \pm 0.09$ & 0.02 & $0.74 \pm 0.16$ & $0.73 \pm 0.16$ & 0.98 & $0.61 \pm 0.15$ & $0.87 \pm 0.17$ & 0.26 \\
\hline $\begin{array}{l}\text { Transplantation-associated } \\
\text { psychological distress }\end{array}$ & $0.67 \pm 0.16$ & $0.58 \pm 0.08$ & 0.60 & $0.66 \pm 0.09$ & $0.54 \pm 0.09$ & 0.38 & $0.56 \pm 0.09$ & $0.64 \pm 0.10$ & 0.56 \\
\hline Total & $0.57 \pm 0.14$ & $0.73 \pm 0.07$ & 0.32 & $0.69 \pm 0.08$ & $0.68 \pm 0.09$ & 0.95 & $0.57 \pm 0.08$ & $0.80 \pm 0.09$ & 0.07 \\
\hline \multicolumn{10}{|l|}{ SF-36 } \\
\hline Physical functioning & $71.3 \pm 6.5$ & $73.8 \pm 3.2$ & 0.74 & $73.5 \pm 4.3$ & $68.1 \pm 4.3$ & 0.38 & $81.7 \pm 3.8$ & $59.9 \pm 4.3$ & $<0.001$ \\
\hline Role - physical & $70.6 \pm 13.4$ & $50.4 \pm 6.6$ & 0.18 & $70.3 \pm 8.2$ & $38.0 \pm 8.3$ & 0.009 & $55.6 \pm 7.2$ & $52.7 \pm 8.2$ & 0.80 \\
\hline Bodily pain & $58.8 \pm 9.4$ & $65.2 \pm 4.7$ & 0.54 & $72.2 \pm 5.6$ & $55.3 \pm 5.6$ & 0.04 & $66.9 \pm 5.0$ & $61.0 \pm 5.8$ & 0.44 \\
\hline General health & $49.6 \pm 8.8$ & $56.0 \pm 4.5$ & 0.52 & $61.0 \pm 5.2$ & $51.6 \pm 5.2$ & 0.21 & $60.8 \pm 4.9$ & $51.8 \pm 5.5$ & 0.23 \\
\hline Vitality & $61.6 \pm 7.3$ & $51.0 \pm 3.7$ & 0.20 & $58.4 \pm 4.2$ & $48.7 \pm 4.2$ & 0.11 & $57.4 \pm 3.9$ & $49.8 \pm 4.6$ & 0.22 \\
\hline Social functioning & $70.3 \pm 8.1$ & $81.3 \pm 4.1$ & 0.23 & $81.7 \pm 4.9$ & $77.9 \pm 5.0$ & 0.6 & $85.4 \pm 4.5$ & $74.3 \pm 5.2$ & 0.12 \\
\hline Role - emotional & $71.1 \pm 11.4$ & $76.8 \pm 5.7$ & 0.66 & $85.4 \pm 6.7$ & $67.3 \pm 7.1$ & 0.08 & $81.4 \pm 6.4$ & $72.0 \pm 7.3$ & 0.35 \\
\hline Mental health & $73.3 \pm 6.2$ & $76.7 \pm 3.1$ & 0.62 & $78.1 \pm 3.6$ & $76.4 \pm 3.7$ & 0.75 & $79.8 \pm 3.4$ & $74.7 \pm 3.9$ & 0.34 \\
\hline
\end{tabular}

*adjusted for age, sex and comorbidity

** adjusted for sex and comorbidity

**** adjusted for age and sex

Some weaknesses of the study should be noted. This study was a cross-sectional study in one hospital with a limited sample size, and all patients were successful renal transplant recipients.

The questionnaire contains items intended to assess side effects of immunosuppressive medication. Hence, the questionnaire can be a useful supplement to other questionnaires in studies of kidney transplantation, in particular in studies of variations in immunosuppressive medication following transplantation.

\section{Conclusion}

In summary, we have demonstrated that the psychometric properties of the Norwegian version of the ESRD-SCL were satisfactory and in line with the German original. Hence, the questionnaire can be recommended for use in future studies. The present study was not designed to evaluate responsiveness, which should be assessed in a longitudinal study.

\section{Competing interests}

The author(s) declare that they have no competing interests.

\section{Authors' contributions}

KS participated in planning and design of the study, organization of data collection, performed the statistical analysis, drafted and revised the manuscript. RG participated in the planning and design of the study, organization of data collection, and critically reviewed the manuscript. Both authors read and approved the final manuscript.

\section{Additional material}

\section{Additional file 1}

The Norwegian version of the End-Stage Renal Disease Symptom Checklist-Transplantation Module (ESRD-SCL). The additional file shows the Norwegian version of the ESRD-SCL, which was translated and validated in the article.

Click here for file

[http://www.biomedcentral.com/content/supplementary/1471-

2369-7-17-S1.doc] 


\section{References}

I. Keown P: Improving quality of life - the new target for transplantation. Transplantation 200I, 72:S67-S74.

2. Rebollo P, Ortega F, Baltar JM, Badia X, Alvarez-Ude F, Diaz-Corte C, Naves M, Navascues RA, Urena A, Alvarez-Grande J: Health related quality of life (HRQOL) of kidney transplanted patients: variables that influence it. Clin Transplant 2000, | 4:199-207.

3. Ponton P, Rupolo GP, Marchini F, Feltrin A, Perin N, Mazzoldi MA, Giacon B, Baldan N, Rigotti P: Quality-of-life change after kidney transplantation. Transplant Proc 200I, 33:I887-9.

4. Jofre RJM, Moreno F, Sanz-Guajardo D, Valderrabano F: Changes in quality of life after renal transplantation. Am J Kidney Dis I998, 32:93-100.

5. Fiebiger W, Mitterbauer C, Oberbauer R: Health-related quality of life outcomes after kidney transplantation. Health Qual Life Outcomes 2004, 2:2.

6. Laupacis A, Pus N, Muirhead N, Wong C, Ferguson B, Keown P: Disease-specific questionnaire for patients with a renal transplant. Nephron 1993, 64:226-31.

7. Franke GH, Reimer J, Kohnle M, Luetkes P, Maehner N, Heemann U: Quality of life in end-stage renal disease patients after successful kidney transplantation: development of the ESRD symptom checklist - transplantation module. Nephron 1999, 83:31-9.

8. Hays RD, Kallich JD, Mapes DL, Coons SJ, Carter WB: Development of the kidney disease quality of life (KDQOL) instrument. Qual Life Res 1994, 3:329-38.

9. Green J, Fukuhara S, Shinzato T, Miura Y, Wada S, Hays RD, Tabata R, Otsuka H, Takai I, Maeda K, Kurokawa K: Translation, cultural adaptation, and initial reliability and multitrait testing of the Kidney Disease Quality of Life instrument for use in Japan. Qual Life Res 200I, I0:93-100.

10. Molsted S, Heaf J, Prescott L, Eidemak I: Reliability testing of the Danish version of the Kidney Disease Quality of Life Short Form. Scand J Urol Nephrol 2005, 39:498-502.

II. Reimer J, Franke GH, Philipp T, Heemann U: Quality of life in kidney recipients: comparison of tacrolimus and cyclosporinemicroemulsion. Clin Transplant 2002, 16:48-54.

12. Franke GH, Yucetin L, Yaman H, Reimer J, Demirbas A: Diseasespecific quality of life in Turkish patients after successful kidney transplantation. Transplant Proc 2006, 38:457-9.

13. Franke GH, Reimer J, Philipp T, Heemann U: Aspects of quality of life through end-stage renal disease. Qual Life Res 2003, 12:103-15.

14. Perrin EB, Aaronson NK, Alonso J, Burnham A, Lohr KN, Patrick DL, Roberts J: Scientific advisory committee instrument review criteria. Medical Outcomes Trust Bulletin 1995, 3:I-IV.

15. Ware JE Jr, Snow KK, Gandek B: SF-36 health survey. Manual and interpretation guide Boston, MA: The Health Institute, New England Medical Center; I993.

16. McHorney CA, Ware JE Jr, Lu JF, Sherbourne CD: The MOS 36item Short-Form Health Survey (SF-36): III. Tests of data quality, scaling assumptions, and reliability across diverse patient groups. Med Care 1994, 32:40-66.

17. Loge JH, Kaasa S: Short Form 36 (SF-36) health survey: normative data from the general Norwegian population. Scand J Soc Med 1998, 26:250-8.

18. Aasebo W, Midtvedt K, Hartmann A, Stavem K: Predictors of health-related quality of life in hypertensive recipients following renal transplantation. Clin Transplant 2005, I 9:756-62.

19. Loge JH, Kaasa S, Hjermstad MJ, Kvien TK: Translation and performance of the Norwegian SF-36 Health Survey in patients with rheumatoid arthritis. I. Data quality, scaling assumptions, reliability, and construct validity. J Clin Epidemiol 1998, 5 I: 1069-76.

20. Cronbach LJ: Coefficient alpha and the internal structure of tests. Psychometrica 1951, 16:297-334.

21. Rebollo P, Ortega F, Ortega T, Valdes C, Garcia-Mendoza M, Gomez E: Spanish validation of the "Kidney Transplant Questionnaire": a useful instrument for assessing health related quality of life in kidney transplant patients. Health Qual Life Outcomes 2003, I:56.

22. Charlson ME, Pompei P, Ales KL, MacKenzie CR: A new method of classifying prognostic comorbidity in longitudinal studies: development and validation. J Chronic Dis 1987, 40:373-83.
23. Nunnally JC, Bernstein IH: Psychometric theory 3rd edition. New York: McGraw-Hill; 1994

24. Hays RD, Anderson R, Revicki DA: Psychometric evaluation and interpretation of health-related quality of life data. In The international assessment of health-related quality of life: Theory, translation, measurement and analysis Edited by: Shumaker SA, Berzon R. Oxford: Rapid Communications; 1995:103-14.

25. Streiner DL, Norman GR: Health measurement scales. A practical guide to their development and use Oxford: Oxford University Press; 1995.

26. Reimer J, Franke GH, Luetkes P, Kohnle M, Philipp T, Heemann U: Quality of life after kidney transplantation - the impact of tacrolimus. Transplant Proc 200I, 33:1924-6.

27. Shield CF III, McGrath MM, Goss TF: Assessment of healthrelated quality of life in kidney transplant patients receiving tacrolimus (FK506)-based versus cyclosporine-based immunosuppression. FK506 Kidney Transplant Study Group. Transplantation 1997, 64:1738-43.

28. Scholler G, Rose M, Neuhaus R, Neuhaus P, Klapp BF: Comparison of cyclosporine $A$ and FK506 with regard to complaints and psychosocial characteristics before and after liver transplantation. Transplant Proc 1997, 29:2491-3.

29. Dew MA, Harris RC, Simmons RG, Roth LH, Armitage JM, Griffith BP: Quality-of-life advantages of FK 506 vs conventional immunosuppressive drug therapy in cardiac transplantation. Transplant Proc 1991, 23:3061-4.

30. Felser I, Wagner S, Depee J, Johnson N, Staschak S, Jain A, Fung J], Starzl TE: Changes in quality of life following conversion from CyA to FK 506 in orthotopic liver transplant patients. Transplant Proc 1991, 23:3032-4.

\section{Pre-publication history}

The pre-publication history for this paper can be accessed here:

http://www.biomedcentral.com/1471-2369/7/17/prepub

Publish with Bio Med Central and every scientist can read your work free of charge

"BioMed Central will be the most significant development for disseminating the results of biomedical research in our lifetime. "

Sir Paul Nurse, Cancer Research UK

Your research papers will be:

- available free of charge to the entire biomedical community

- peer reviewed and published immediately upon acceptance

- cited in PubMed and archived on PubMed Central

- yours - you keep the copyright

Submit your manuscript here:

http://www.biomedcentral.com/info/publishing_adv.asp
BioMedcentral 